\title{
Interactions between aquatic vegetation, hydraulics and fine sediment
}

\author{
Hamish Biggs ${ }^{1}$, Arman Haddadchi², and Murray Hicks² \\ ${ }^{1}$ National Institute of Water and Atmospheric Research \\ ${ }^{2}$ National Institute of Water and Atmospheric Research Christchurch Office
}

December 8, 2020

\begin{abstract}
Aquatic vegetation, hydraulics and sediment transport have complex interactions that are not yet well understood. These interactions are important for sediment conveyance, sediment sequestration, phasing of sediment delivery from runoff events, and management of ecosystem health in lowland streams. To address this knowledge gap detailed field measurements of sediment transport through natural flexible aquatic vegetation are required to supplement and validate laboratory results. This paper contributes a field study of suspended sediment transport through aquatic vegetation and includes mechanical removal of aquatic vegetation with a weed cutting boat. It also provides methods to quantify vegetation cover through remote sensing with Unmanned Aerial Vehicles (UAVs) and estimate biomass from ground truth sampling. Suspended sediment concentrations were highly dependent on aquatic vegetation abundance, and the distance upstream that had been cleared of aquatic vegetation. When the study reach was fully vegetated (i.e. cover $>80 \%$ ), the maximum recorded SSC was $14.6 \mathrm{~g} / \mathrm{m}^{3}$ (during a fresh with discharge of $2.47 \mathrm{~m}^{3} / \mathrm{s}$ ), during weed cutting operations SSC was $76.8 \mathrm{~g} / \mathrm{m}^{3}$ at $0.84 \mathrm{~m}^{3} / \mathrm{s}$ (weedcutting boat $0.5-1 \mathrm{~km}$ upstream from study reach), however following weed cutting operations (4.6 $\mathrm{km}$ cleared upstream), SSC was $139.0 \mathrm{~g} / \mathrm{m}^{3}$ at a discharge of $1.52 \mathrm{~m}^{3} / \mathrm{s}$. The data indicates that fine sediment was being sequestered by aquatic vegetation and likely remobilised after vegetation removal. Investigation of suspended sediment spatial dynamics illustrated changes in particle size distribution due to preferential settling of coarse particles within aquatic vegetation. Hydraulic resistance in the study reach (parameterized by Manning's n) dropped by over $70 \%$ following vegetation cutting. Prior to cutting hydraulic resistance was discharge dependent, while post cutting hydraulic resistance was approximately invariant of discharge. Aerial surveying captured interesting changes in aquatic vegetation cover, where some very dense regions of aquatic vegetation were naturally removed leaving behind unvegetated riverbed and fine sediment.
\end{abstract}

\section{Hosted file}

Biggs, Haddadchi and Hicks - Aquatic vegetation, hydraulics and fine sediment - HYP.pdf available at https://authorea.com/users/381869/articles/497789-interactions-between-aquaticvegetation-hydraulics-and-fine-sediment 

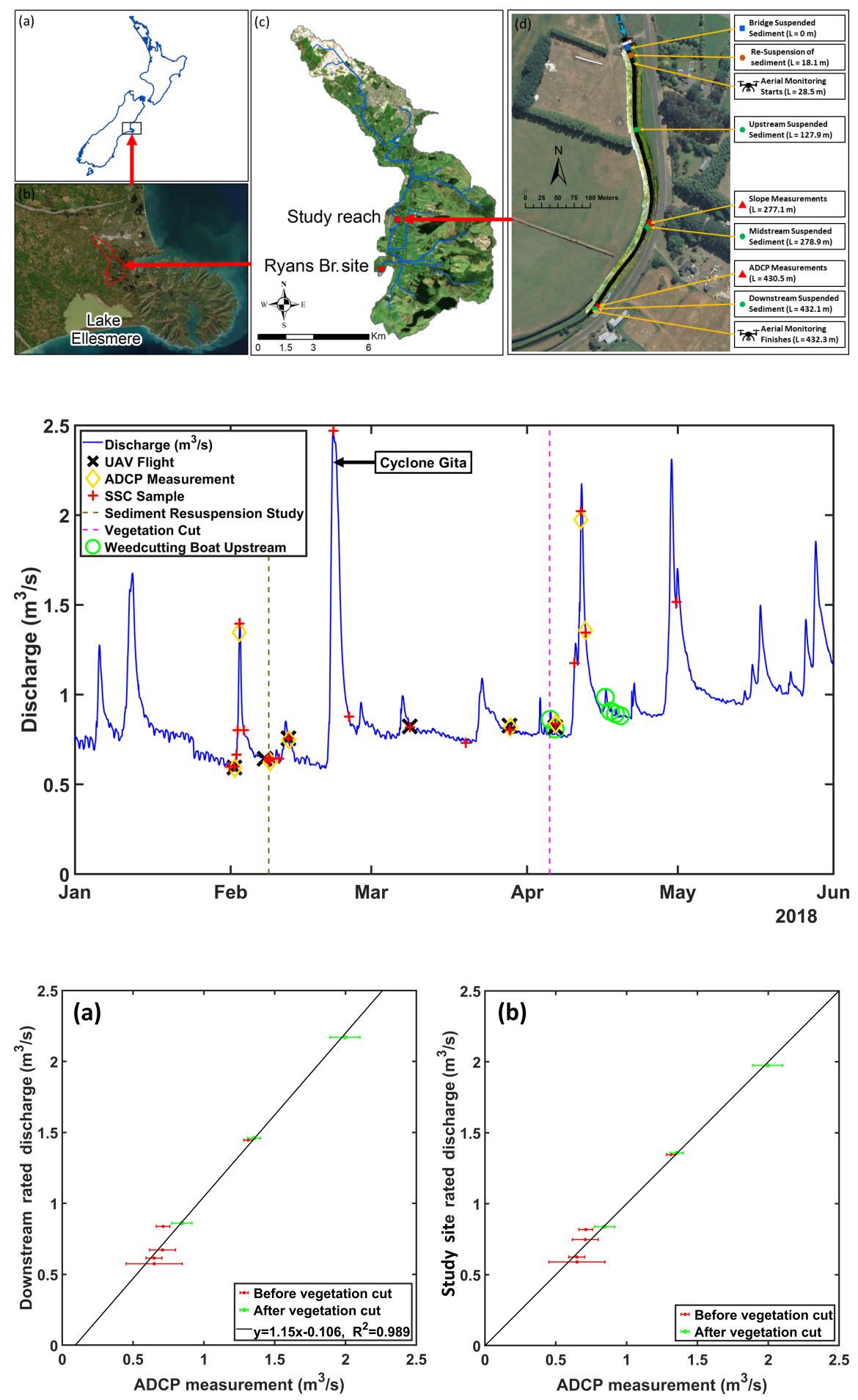

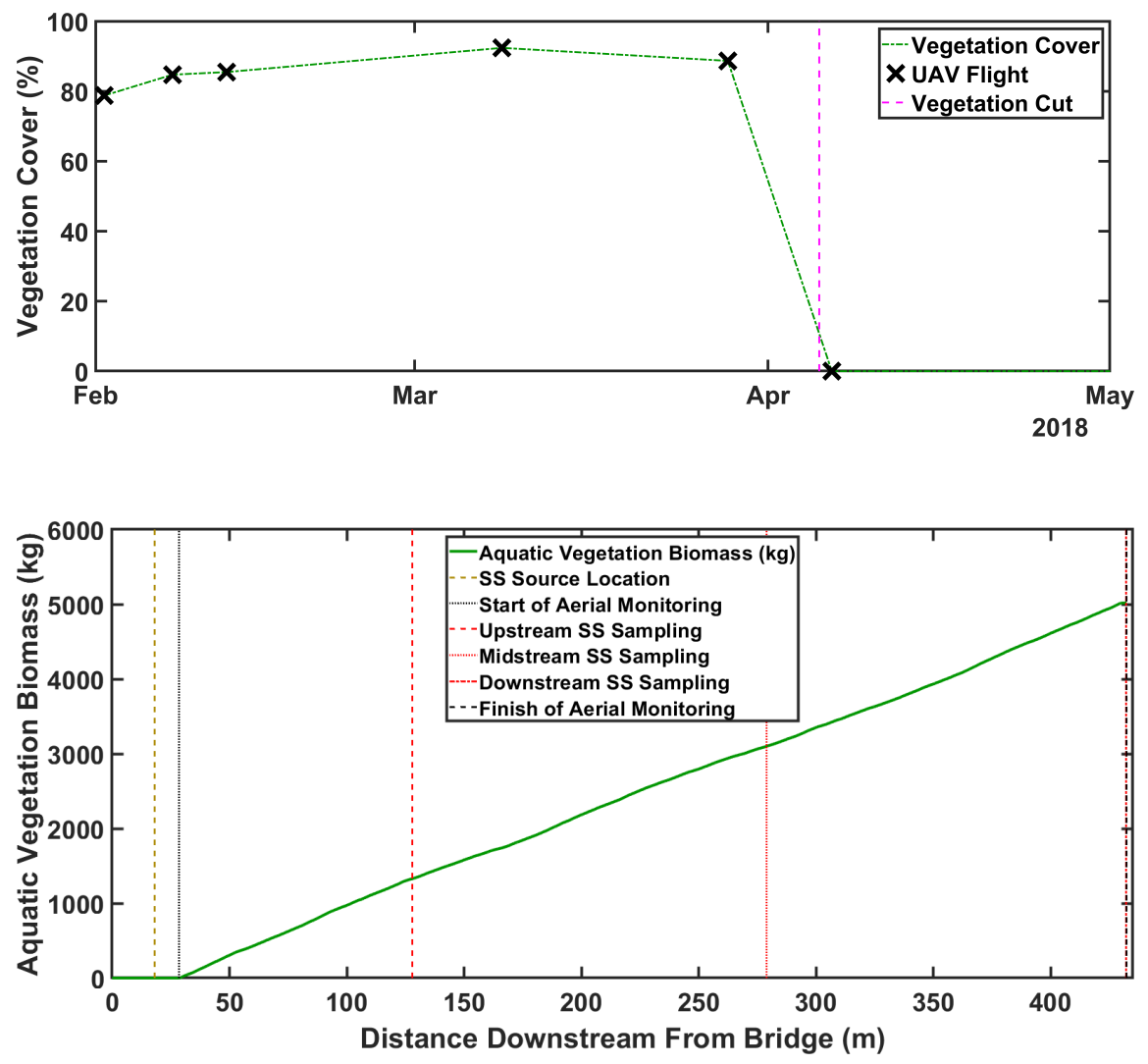

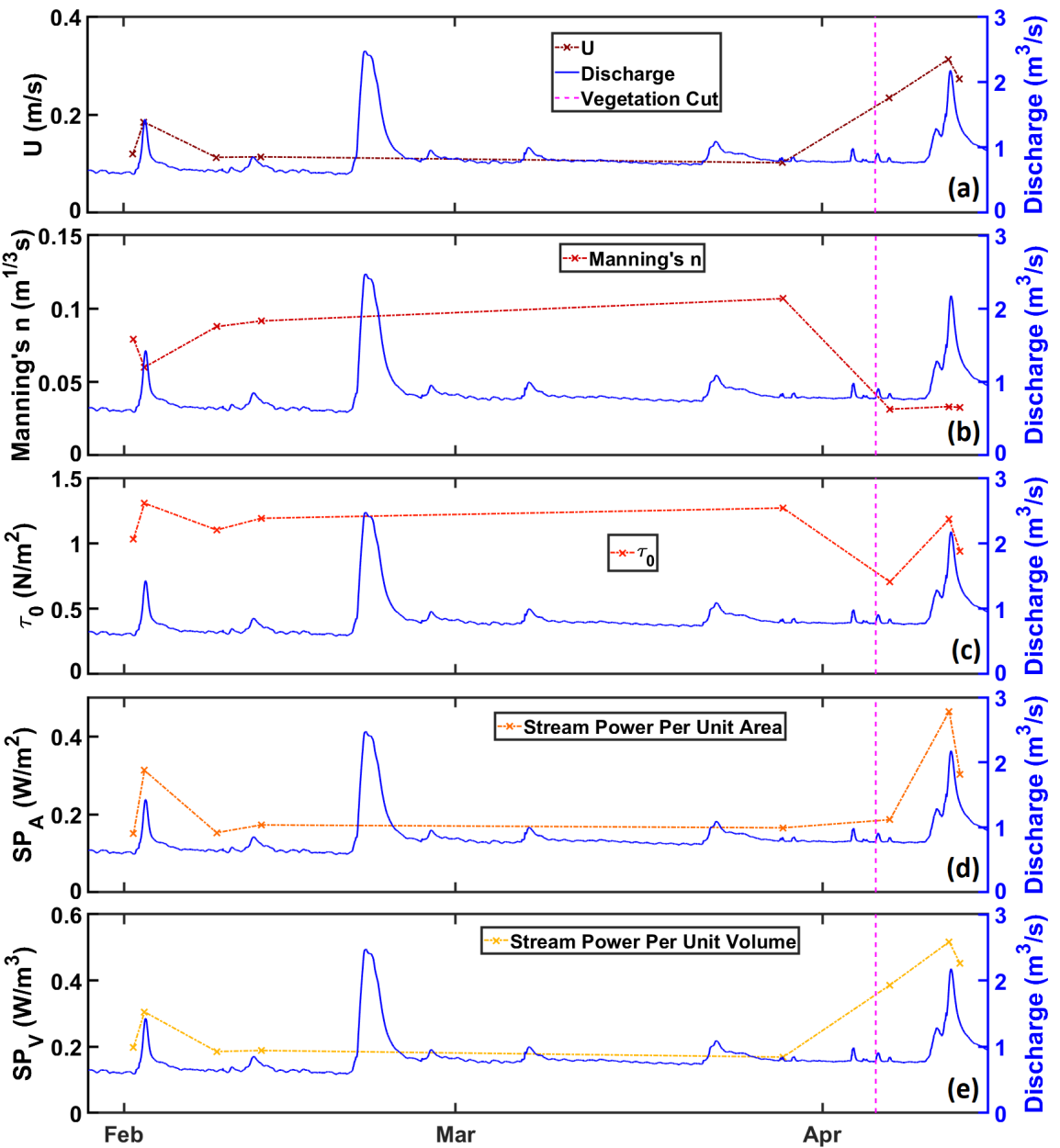

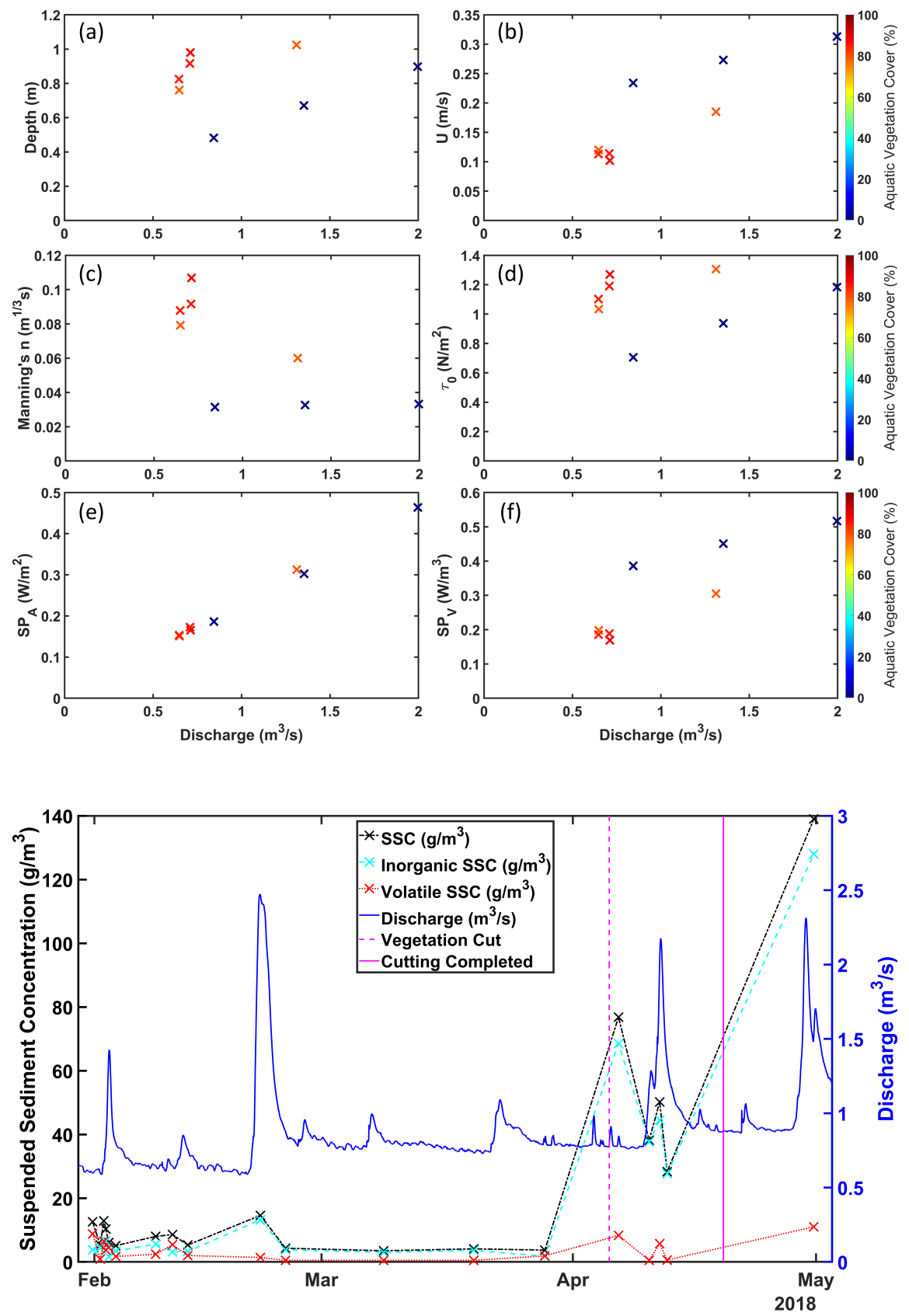

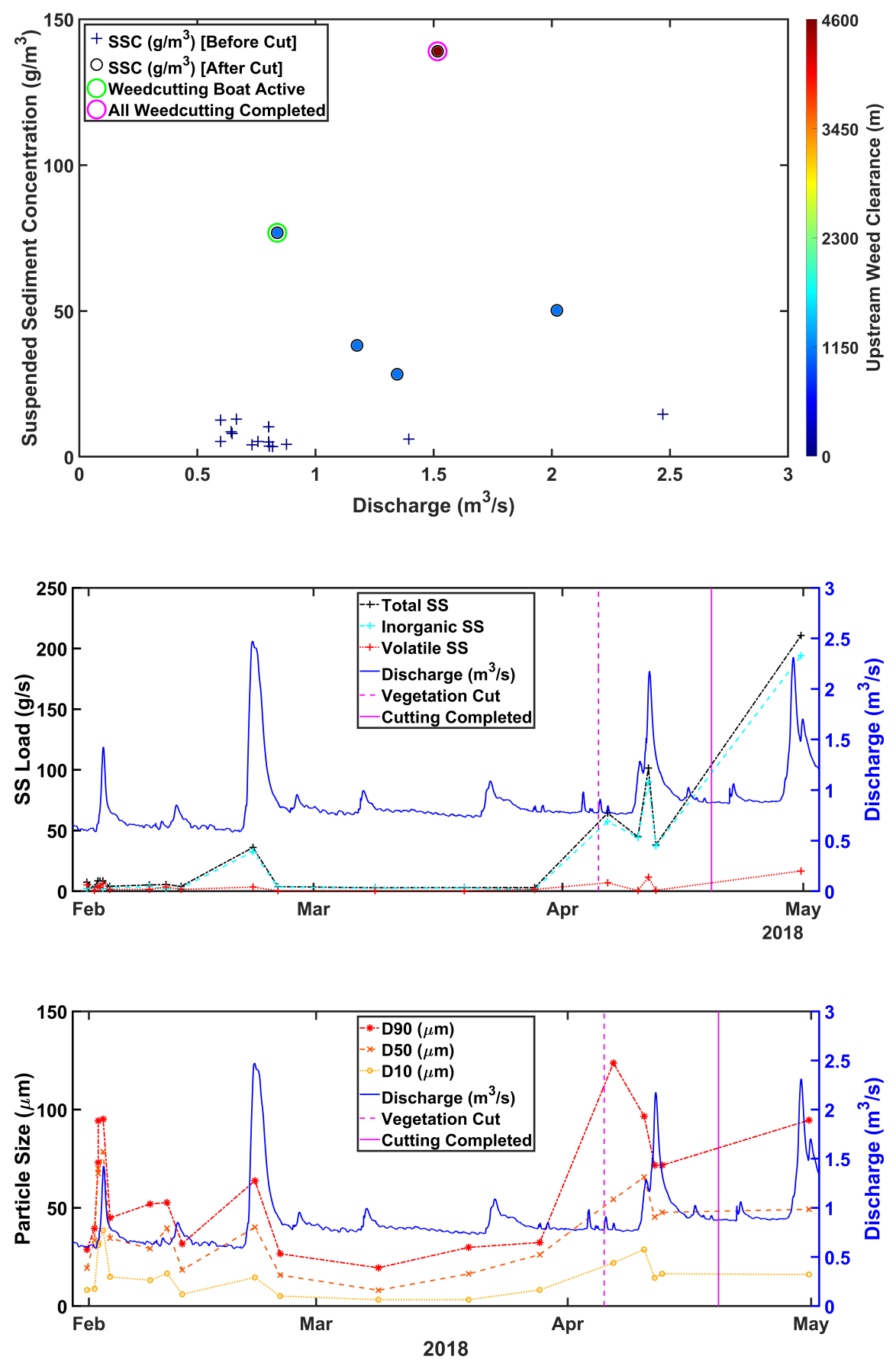

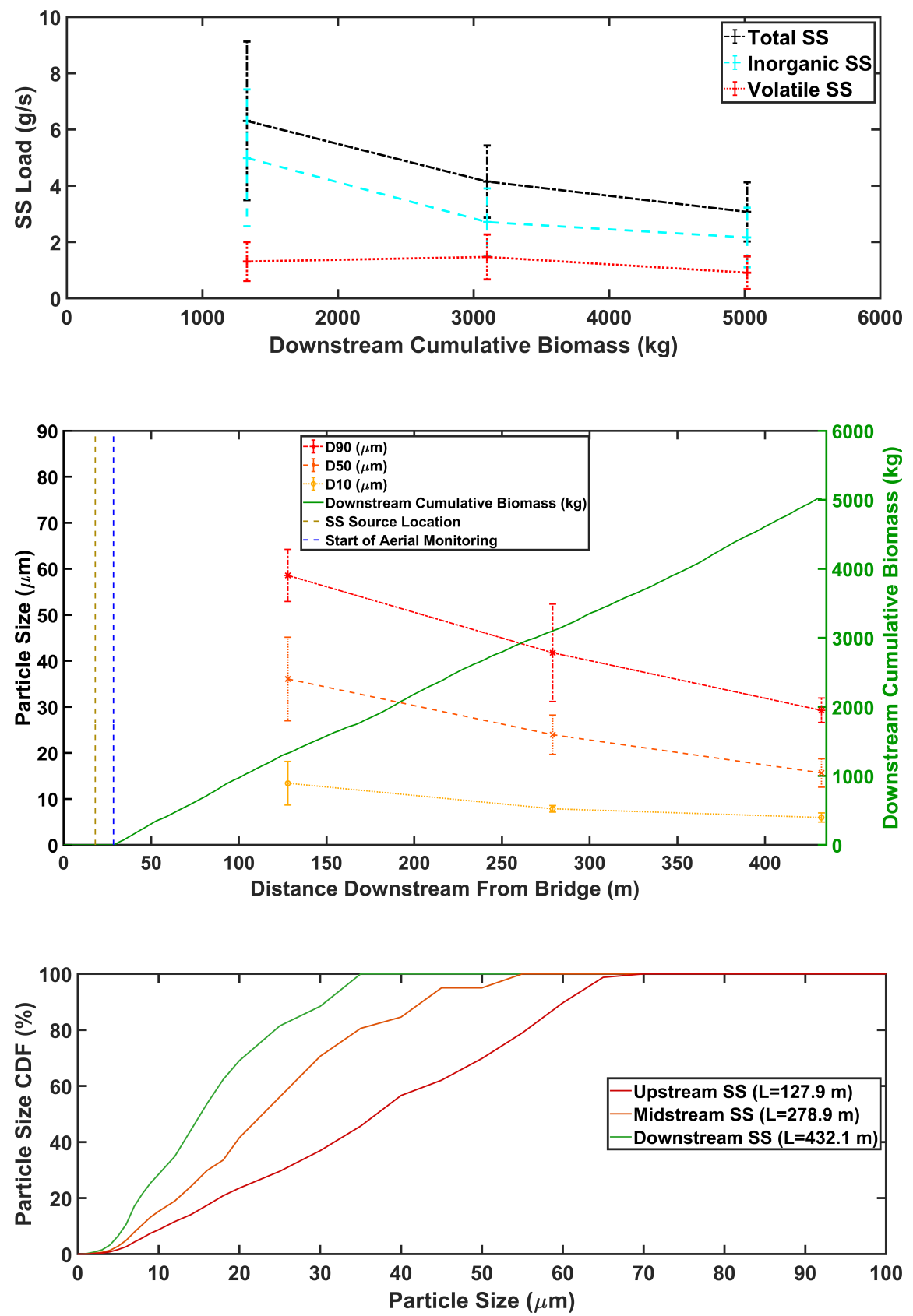

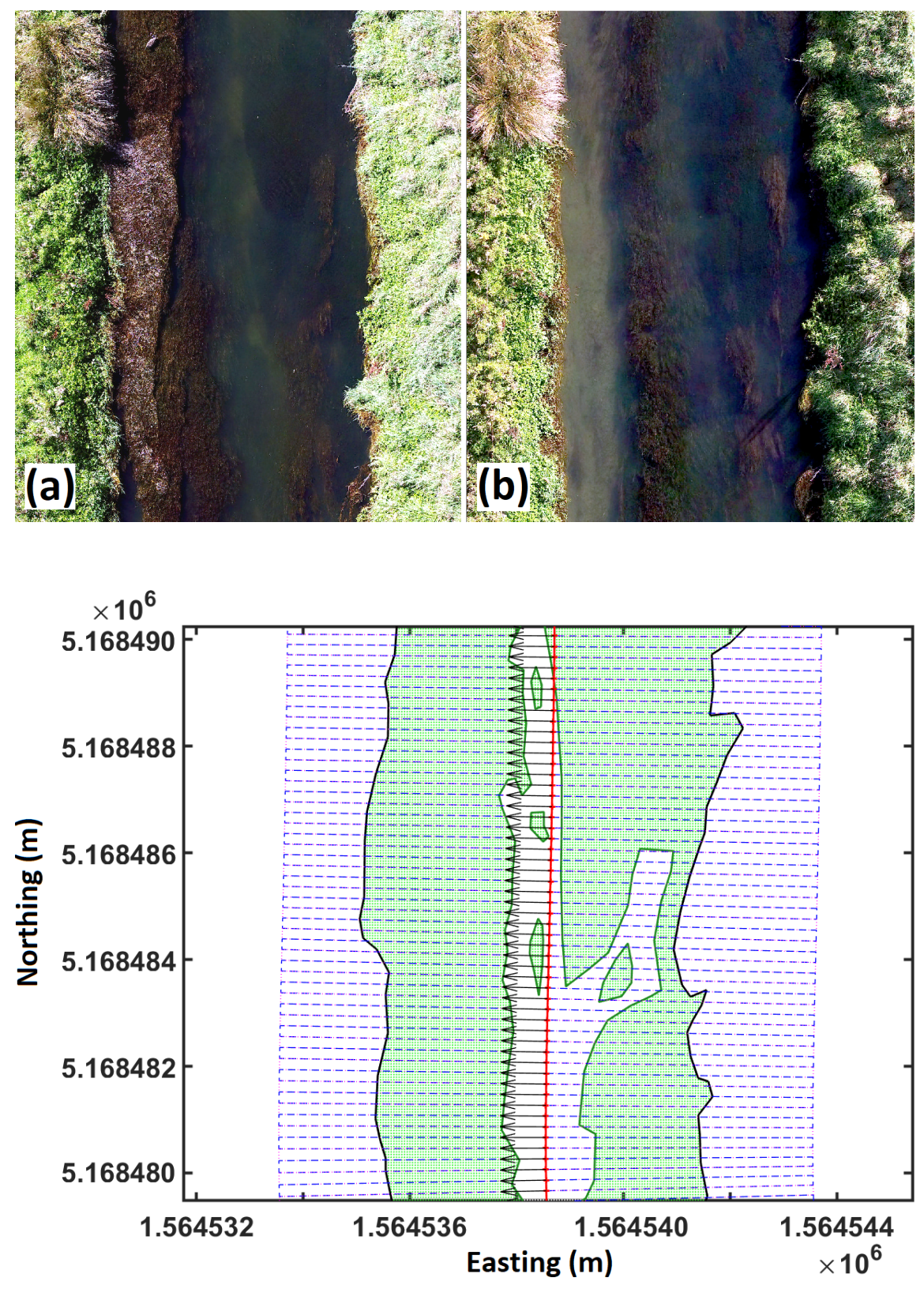